\section{THE FINCHLEY SEWAGE FARM.}

$\mathrm{BY}$

HenRY Kenwood, M.B., D.P.H, F.C.S., M.O.H. for Finchley.

THE superintendent has during the year $\mathbf{r} 895$ removed a large quantity of useless material (i.e. the natural soil containing 80 per cent. clay) from the sixteen filter beds of the sewage farm, and it is the aim of the council to entirely replace it as soon as possible by the hard core and burned cinder ash which is procured from the dust collected in the district.

With the filter beds hitherto so inefficient, it is a matter of some surprise that the effuents should have been so satisfactory; but it must be remembered that in addition to a very thorough chemical treatment of the sewage, the effuent from the settling tanks is not entirely dependent upon filter beds for its further purification, for it is subsequently exposed to considerable surface flow over grass fields before it enters the brook. It is wellknown that such surface flow, even when over a stiff clay soil, brings about an improvement in the effluent which is remarkable, in that it far exceeds that which would be conjectured on chemical and physical grounds.

During the year I have performed a very large number of analyses, with the object of ascertaining if $(a)$ we were tsing more lime or more alum than was necessary; $(b)$ or whether these two substances were combined in their best proportions.

I considered that there was probably some waste of chemicals, except perhaps in those cases where the sewage came up very black and thick, and I thought that perhaps some saving could be effected in chemicals without in any way affecting the satisfactory character of the effluent; and if so, the amount and causticity of the sludge would also be thereby reduced-another very positive advantage.

The recommendations of the late Dr. Tidy were that the reagents employed should be alum and lime, and that they should be added to the amount of 7 and to grains respectively to the gallon of sewage.

While conducting the long series of experiments embracing nearly Ioo analyses, I soon found that it was useless comparing the results of work upon sewage taken on different days. I found that even though the sewage of one day be to physical tests the same (even the specific gravity being identical) with that of another day, the effect of equal amounts of chemical on the two samples may vary. It is extremely difficult to account for the discrepancies which I encountered under this head. Obviously the nature of the original refuse matter which finds its way into the sewers cannot vary much in Finchley from day to day, and the only explanation I have to offer is that the sewage was collected at different hours, and it is conceivable that the sewage may vary in nature, at different hours, throughout the same day.

In every case I worked with fresh sewage pumped up into cans, so the difference in the precipitability of the sewage was not due to stages in staleness and decomposition of such sewage. I performed experiments to this end, and found that more matter can be chemically precipitated from fresh sewage than from stale. A sample of fresh sewage, for instance, containing 180 parts per 100,000 of total solids yielded a supernatant fluid showing 86 parts per 100,000 in 6 hours from the addition of the precipitants, whereas the same sewage after 24 hours gave 93 parts, and after 48 hours, 94. The probable explanation is that the organic matter quickly decomposes and thereby breaks up into much finer particles, which may escape being carried down by the chemical precipitant, and probably the gases which are given off in increasing quantities as fermentation and putrefaction advances, by their constant bubbling up through the sewage, keep lifting up the lighter particles, and thus prevent them from depositing completely.

These facts, then, point to one conclusion only, and serve to drive home two important truths, i.e., (a) There is a distinct advantage-so far as the purity of the effluent is concerned-in treating the sewage as fresh as possible; $(b)$ There is a disadvantage in allowing sewage to remain in the tanks for more than a few hours.

I experimented, therefore, upon fresh average samples of the Finchley sewage; and the experiments were conducted in many series upon the same sewage taken at the same time from the sewer; the figures of the analyses were all submitted to the sanitary committee.

I first took many measured quantities of the fresh sewage and treated these with known and varying amounts of lime, and my best results were obtained when 9 grains to the gallon of lime were added to what one may classify as an average sample of sewage-that is to say less than 9 grains gave less satisfactory results, but more than 9 grains did not effect any appreciable improvement in the effluent.

Similar experiments were performed with alum, with the result that $\mathrm{x} 2$ grains were found the most satisfactory amount to use.

Next the two substances were combined in all proportions within the limits of Io grains of one to I grain of the other, and after verifying results by a series of control experiments, I found that 7 grains of lime and 5 of alum gave the best allround results with average fresh sewage of the district.

I found that 7 grains to the gallon of lime, and 5 of alum, separate about 25 per cent. of the total solids in solution in the sewage as well as about 90 per cent. of the solids in suspension. Alum acts by yielding a flocculent precipitate, and this settles more slowly than the lime precipitate; it is 
more easily listurbed after settlement; and alum tends to form a certain amount of floating scum; these are distinct drawbacks to its use So far as clarification of the sewage was concerned, better results were got by ro grains to the gallon of lime than by 5 grains of lime and 5 of alum; i.e., there is about equal clarification, but this is more quickly effected. Lime is only about half the price of an equal weight of alum, and the question naturally arises as to why the alum should be employed at all, and why its place should not be taken by an equal amount of lime.

The only advantages that can possibly accrue from the use of the alum are the following:-( $\mathrm{r})$ The effluent and sludge from pure lime treatment are strongly alkaline (too strong, in fact, to render either of much value to vegetation) and the alum tends to neutralise this alkalinity. (2) With a pure lime effluent there is a tendency for a secondary decomposition to set in, with the rec ult that it gives off offensive smells after standingalum tends to check this decomposition and consequent evolution of smells. (3) If too much lime is employed, some of the offensive matter that was originally in suspension gets dissolved, held in solution and not precipitated-and a less pure effuent results.

The next obvious question is whether something may not be substituted for the alum which will give a heavier precipitate which will settle more rapidly, which will at least equal the alum in its clarifying and purifying effects, and which will tend to check secondary decomposition in the effuent at least as effectually as the alum.

My experiments with carbferalum, which is a mixture of alum, protosulphate of iron, and carbon, furnish results but little better than those from an equivalent amount of lime; but the protosulphate of iron is employed along with lime on many farms and also at the sewage outfall works for the Metropolis, and I have carefully gone into the relative powers and merits of this iron salt and alum.

I find from many experiments that the protosulphate possesses all the advantages (as a precipitant) of the alum, with none of its disadvantages, and that the results of the employment of $2 \frac{1}{2}$ grains to the gallon of this re-agent are in the main as efficient as 5 grains of alum, and that the iron excels the alum in its power of keeping the sludge and effluent sweet. It is necessary that the lime should be added first, so as to ensure marked alkalinity of the sewage.

To sum up, $I$ find that a mixture of 5 grains to the gallon of lime, and $2 \frac{1}{2}$ grains to the gallon of ferrous sulphate give better all-round results than even Dr. Tidy's recommendation of ro grains of lime, and 7 of alumina.

$$
\text { The cost of lime is ... } \ldots \text { protosulphate of iron ", } \mathscr{L}_{2} \mathrm{r} \text { per ton. }
$$

The samples of effuent collected since the lime and ferrous sulphate have been employed, in accordance with my recommendation, compare favourably with those obtained by the previous treatment, and the suggestion has effected a saving in the outlay upon chemical precipitants.

\section{POLLUTION OF THE CLYDE AND ITS TRIBUTARIES BY COAL-DROSS DRESSINGS.*}

BY

JNo. T. Wrrson, M.D., D.P.H., County Medical Officer of Lanark.

THe inspections and reports made during the year were largely concerned with pollutions by coal-dross washings. There are fifty collieries in the County-eight in the Upper, forty-one in the Middle, and one in the Lower Ward-where this process is carried on, and the pollution affects various interests.

Although in dross-washing, the object aimed at is in all cases the same, viz., the separation of the small pieces of coal from coal-dust and earthy matter by elutriation, the methods by which this is attained vary considerably. The only important difference in the modus operandi I need refer to here is that which relates to the quantity of water used.

In one method commonly employed, the water, when once charged with detritus, is allowed to flow away; while in another the works are so arranged that the same water is used over and over again. In the latter method the polluted water as discharged is made to flow back slowly through a. series of settling tanks to the place where it is utilised, and in its course deposits the greater portion of the suspended matter before being used again. In such a method, the amount of effluent flowing away from the works is comparatively small, while the pollution and purification of the water is essentially one process.

Of $x 9$ effluents examined during 1895 at the Public Health Laboratory, the number of grains per gallon in suspension varied from 7 to 5,106 ; of grains per gallon dissolved, from 22 to $\times 54$.

The amount of solids in suspension indicates the extent of the pollution, which, it will be observed, is very serious in some, while in others there is none.

That the pollution is entirely due to solid matter in suspension may be seen by allowing a sample of dross-washings to stand for a few hours, when it separates into a black deposit and a clear supernatant liquid. In the samples examined from four of the above pits, this deposit formed from onehalf to ten per cent. of the total volume, the weight of the dried deposit varied from 66 to over 2,000 grains per gallon, and, on ignition, was reduced to

* From Dr. Wilson's Annual Report for 1895 . 